\title{
Views of physicians and patients with chronic conditions on generic medicines in Greece after the introduction of measures to promote their consumption: findings from a qualitative study
}

\author{
Eleftheria Karampli, MSc; Efstathia Triga, MSc; Vasiliki Tsiantou, MSc; Kostas Athanasakis, PhD; John \\ Kyriopoulos, PhD
}

\begin{abstract}
Introduction/Study objectives: Generic medicines uptake is widely acknowledged as a key pharmaceutical policy measure towards cost containment and rational resource allocation. In Greece, due to the persistently low penetration of generics in the pharmaceutical market, a series of policy measures aiming to reverse this trend were implemented during the last years. The aim of the present study was to explore the perceptions and experiences of physicians and patients towards generic medicines as well as the acceptability of the policies implemented. Methods: A qualitative approach, based on semi-structured interviews to physicians and chronically ill patients residing in the region of Attica formed the basis of the analysis. Recruitment of physicians and patients was performed using a combination of convenience and snowball sampling techniques. Interviews were audio-recorded, transcribed and content analysed, according to international guidelines for qualitative research.

Results/Discussion: Nine physicians (general internists and cardiologists), and nine patients suffering from hypertension, diabetes mellitus and hyperlipidemia participated in the survey. Physicians' views on generics were positive, although concerns were raised regarding the monitoring mechanisms and the reliability of companies producing generics. Patients were more hesitant to express their opinion on generics because they felt that they were not adequately informed. Prescribing is a multi-criteria decision, whereas for patients the choice of medicine is made by their physician. Cost was not an important factor for both groups. Policy measures on generics were generally acceptable in the case of physicians and there were mixed opinions in the group of patients. Both groups stressed the need for more and reliable information regarding generics.

Conclusion: Patient and physician attitudes can 'make or break' even a perfectly planned healthcare policy. Taking into consideration the information available in studies such as the present one, can aid decision-makers towards the design and implementation of viable policies in the sensitive field of generics uptake.
\end{abstract}

Keywords: Generics, medicines consumption, patients, pharmaceutical policy, physicians, prescribing

\section{Introduction}

Medicines have undoubtedly made important contributions to the improvement of the population health status in developed/ developing countries over the last decades. However, the growth rates of pharmaceutical expenditure over the same period has by far exceeded the growth rate of the economy in general [1, 2], raising concerns about the sustainability of social security systems. The latter has led European governments towards the implementation of a series of reforms in order to contain pharmaceutical expenditure and increase the efficiency of healthcare spending [3]. Pharmaceutical policies targeted to the increased uptake and use of generic medicines is considered a key solution for expenditure control and rational allocation of resources [4]. In this sense and, partially, in response to the economic crisis of 2008, the majority of European countries implemented pharmaceutical sector reforms in order to contain public expenditure on pharmaceuticals [5]. Policies to further increase the market share of generics were among the most frequent measures introduced $[6,7]$.

In Greece, the First Economic Adjustment Programme (EAP) that was agreed under a memorandum of understanding (MoU) with the European Union (EU), the International Monetary Fund (IMF) and the European Central Bank (ECB) set specific expenditure targets for public expenditure on health and pharmaceuticals [8]. Specifically, public health expenditure and public pharmaceutical expenditure were to be reduced to $6 \%$ and $1 \%$ of the country's gross domestic product (GDP) (as per the EU average), respectively. In this direction, emphasis was given -among others- to the increase of the use of generic medicines (the so-called 'generics penetration'), as Greece historically had persistently lower market shares for generics both in terms of value and volume [9] compared to its European peers. Following the positive experience of International Nonproprietary Name (INN) prescribing in Europe [10], in terms of implementation [11], efficacy [12] and potential cost savings [13] a ministerial decision regarding the universal and mandatory implementation of INN prescribing in both the hospital and outpatient setting was implemented in 2012. However, this was not accompanied by measures that could positively influence a workable implementation of this policy such as physician training [11] - thus it faced resistance from the physicians. Further measures towards generics penetration included reductions in prices of generics;

Author for correspondence: Efstathia Triga, MSc, Research Associate, Department of Health Economics, National School of Public Health, 196 Alexandras Ave, GR-11521 Athens, Greece

Submitted: 19 January 2016; Revised: 8 April 2016; Accepted: 8 April 2016; Published online first: 22 April 2016 
compulsory e-prescription by physicians and introduction of prescription guidelines; reintroduction of a positive list in combination with a reference price system. Certain exceptions to INN prescribing were foreseen. Physicians were also allowed to prescribe by brand name up to a maximum of $15 \%$ of prescriptions written. Minimum prescription targets for generic medicines were also introduced in 2014 [14]. Both INN prescribing and mandatory prescribing quotas were highly debated by the pharmaceutical industry and health professionals, especially physicians and pharmacists [15]. In April 2015, physicians were given the option of suggesting the commercial name in parallel to INN prescribing, however, this provision was recently revoked. According to the goal set in the Third EAP for Greece which was signed in August 2015 [16], the target market share of generics was set to increase by $40 \%$ (in volume) by December 2015 and 60\% by December 2016 in the outpatient setting.

However, despite the positive attitude of Greek physicians towards generics and their belief that a policy towards the promotion of generics could result in increases in prescribing [17] and despite the introduction of several measures to encourage generics prescribing and consumption [18], their market share in the outpatient setting still remains low at $22 \%$ in volume [19]. This indicates that the implemented policies did not significantly affect the physicians' prescribing behaviour regarding generics and that the measures severely underperformed. Apart from that, there is a paucity of data regarding the attitudes and behaviour of patients in Greece towards generic medicines, a fact that prohibits the planning and workable implementation of pharmaceutical policies aiming at the uptake of generics.

In light of the above, the objective of this study was to explore the perceptions and experiences of physicians and patients with chronic conditions towards generic medicines as well as the acceptability of the measures that were implemented in aim to promote generics' consumption in Greece, a country deeply affected by the economic crisis. In parallel, the present study aimed at eliciting patients' attitudes towards generic medicines, and their knowledge regarding the related policy measures.

\section{Method}

\section{Study design}

A qualitative research design was considered appropriate for the purpose of this study. A qualitative approach enables the researcher to better understand a social phenomenon within its context [20]. Semi-structured interviews were used for data collection. According to this method the interviewer uses a series of general questions but is also able to vary the sequence of questions and ask additional ones, so that the conversation between the interviewer and interviewee is developed in a free atmosphere in order to explore in depth the attitudes of informants [21].

\section{Participants and settings}

Two medical specialties were selected for the physicians' sample: cardiologists and general internists. This selection was based on the findings of a countrywide study [22], which showed that patients' visits to physicians were most frequently made to these two specialties. A second reason for focusing on cardiologists and internists was the fact that these specialties are the main prescribers of antihypertensive medicines and statins. The latter were among the ten most frequently prescribed therapeutic classes of prescription medicines according to the Ministerial Decision on the implementation of INN prescribing issued in March 2012.

Recruitment of physicians was performed using a combination of convenience and snowball sampling. Convenience sampling refers to the sampling of individuals that are easily accessible and most likely to accept to participate. In the snowballing technique, the initial respondents are asked to suggest other possible interviewees that fulfill the inclusion criteria in the study [23].

Interviews with patients took place following the completion of the physicians' interviews. From the physicians' responses it was derived that they mainly prescribed medicines for patients with hypertension, hyperlipidemia and type-2 diabetes. Therefore, patients with these chronic conditions were invited to participate using also convenience and snowballing sampling techniques.

In both cases participants were informed about the study via an invitation letter, which described the aim of the study and the process of interviewing. The invitation letter also assured participants of the protection of their anonymity and explicitly stated that the study results would be used only for scientific purposes. Participants provided written or oral consent. None of the participants received compensation. Ethical approval was obtained from the Bioethics Committee of the National School of Public Health (Athens, Greece).

\section{Interview guide development and analysis}

An interview guide was developed for each group of participants based on the study research objectives. Questions on sources of information on medicines in general, perceptions on generics, attitudes towards generics prescribing/consumption and views on INN prescribing and generics substitution were common in both interview guides. The physicians' interview guide also included questions regarding their prescribing decisions, as well as their views on pharmacovigilance and policy measures for generics, i.e. electronic prescribing, prescribing guidelines, prescribing quotas. The latter were considered difficult for patients to evaluate and thus were not included in their interview guide.

Pilot interviews with two physicians and two patients were conducted and necessary changes were made to the interview guides. All interviews with study participants were performed by the same researcher Efstathia Triga (ET). Participants also completed a short form on demographic characteristics. Each interview was audio-recorded, transcribed verbatim (ET), anonymized and analysed manually using qualitative content analysis [24]. Specifically, after the first two interviews for each group were performed, transcripts to be reviewed in full were assigned to Eleftheria Karampli (EK) and ET who each compiled a proposed list of codes. Only manifest content was considered Codes were grouped in categories using hierarchical coding. The procedure was mostly deductive and topics included in the interview guide were used as a background for developing categories. The coding scheme was discussed in a team meeting and changes were implemented following consensus from the team. ET subsequently indexed each new interview transcript and performed the initial analysis. Recruitment of participants ended at the point of data saturation, i.e. when the information 
collected produced little or no change to the coding scheme (as operationalized by Guest et al. [25]). Another member of the research team (EK) reviewed all coded manuscripts and differences were resolved in a team meeting. All interviews, coding and analysis were performed in the Greek language.

\section{Results}

In total, (10) physicians (6 through convenience sampling and 4 through snowballing technique), and (11) patients with chronic conditions were invited to participate in the study. Participating physicians introduced (2) of the invited patients and the rest of them were recruited based on the snowballing technique. Eighteen participants agreed to participate ( 9 from each group) and were interviewed. All participants resided in the region of Attica.

Interviews with physicians took place between 15 February and 1 March 2013 and lasted on average 30 minutes. Six were faceto-face interviews, which took place at the physician's office and three were telephone interviews. Phone interviews were conducted in the cases where a face-to-face appointment could not be scheduled. Phone interviews were also audio-recorded after participants gave oral consent.

Interviews with patients took place from 29 March 2013, at a location of their choice and had an average duration of 20 minutes. Participants' demographic characteristics are presented in Supplementary Material, Table 1.

Content analysis revealed three main categories from both patients' and physicians' interviews. These categories and their subcategories are presented in Supplementary Material, Table 2.

\section{A. Physicians}

Physicians' quotes are presented in Table 1.

\section{Category 1: Perceptions about generics and the need to strengthen quality assurance mechanisms in the Greek market}

\section{1a. Views on the current situation}

When commenting on generic medicines in general, physicians expressed varying views. They tended to make more general comments and referred to both positive aspects and issues of concern regarding the situation in the Greek market. The positive comments that were documented on generics regarded their lower cost and the long-term presence of trustworthy companies with whose products physicians in Greece are familiar. However, those that held a positive view on generics stressed that it was conditional on the quality of the product.

The problematic issues regarding generics that were mentioned by physicians were their cost relative to the reference (off-patent) product, the negative image that was created by the mass media, patients' reservations towards their use and the lack of trust in the regulatory mechanisms and in some of the pharmaceutical companies that distribute generics in Greece.

\section{1b. Safety and effectiveness of generics}

Regarding the effectiveness and safety of generics in specific, most participants held the view that generics that were available at the time of the survey in the Greek market were safe (7/9) and effective (7/9). Participants' positive view was based on the general experience of Greek physicians with generics and/ or their personal experience with prescribing (and in one case consuming) generics. In the latter case, participants tended to clarify that their views with regards to the effectiveness and safety of generics compared to the originator products would apply only to the products that they used; they were hesitant to comment on all generic drug products available in the Greek market. They also expressed positive opinions regarding the existing quality controls and marketing authorization requirements in Greece (4/9). Another argument that was mentioned was that it is not in the commercial interests of generics companies to market products that are not effective.

The reservations regarding the effectiveness and safety of generic drug products were mostly on the effectiveness of the monitoring mechanisms in place (3/9), the reliability of companies that produce and/or market generics (5/9), the quality of bioequivalence studies and the suitability of generics in the case of medicines with narrow therapeutic range (3/9). As was previously mentioned, the reliability of generics companies was a matter of concern. Many physicians tended to distinguish between those companies that have been present in the Greek market for many years and whose products they have been prescribed to patients, and, on the contrary, they expressed concerns regarding the new players in the market (6/9). Generics manufactured by Greek companies were often used as an example of established companies (4/9).

According to the physicians, a company would be characterized as reliable if it had a presence in the pharmaceutical market for an 'adequate' (according to the physician's perception) period of time in order to show positive results for its products and if it had provided bioequivalence studies performed in acknowledged centres. The country of origin was also mentioned as a criterion. Although other criteria, such as a sufficient sales network or the quality of the informational material were also mentioned, they were not considered as important as the aforementioned characteristics. In this view, the need for competent authorities that could ensure that companies are reliable and that generic drug products available in the Greek market are of high quality was emphasized by all participants.

\section{1c. Sources of information on generics}

Physicians use a variety of information sources on generic medicines including scientific, commercial and mass media sources. The most frequently mentioned source of information was pharmaceutical companies via their representatives and promotional material (8/9). Additional sources of information included the international literature, the products' monographs, publications by medical associations, articles in online newspapers (6/9), and also feedback from patients and other physicians regarding their experience with the treatment (2/9). The lack of information from official regulatory bodies was also raised as a reason (2/9). The type of information on a generic drug product that physicians take into consideration relates to the product's bioequivalence report, safety profile, side effects, effectiveness and also results of relative effectiveness studies in real-life settings. 


\section{Table 1: Quotes on categories and subcategories from physicians}

Category 1: Perceptions about generics and the need to strengthen quality assurance mechanisms in the Greek market

(A) Views on the current situation - Quotes

'That generics have low prices is very good ...' (D1)

'Anyway I have been using generic medicines for a long time, bence I have a positive opinion ... but I want generics with a brand name, I prefer to use branded products I don't like to just prescribe a preparation... This is my opinion on generics, yes to generics but under terms.' (D3)

I don't hold a positive or negative view on generics, the point is that when the medicine that you use, its content in active substance is at the required level, on the basis of checks and definitions that are established and certified for each company then we can use generic medicines, as long as there are clear rules on how a product is certified, produced and promoted ...' (D7)

'.. The problem is that not all companies that produce generics are inspected, this is my opinion. There are companies that produce reliable generics and cheaper, this is very good but not all companies are like that and you don't know what [product] to completely trust' (D1)

'We physicians cannot evaluate them, it is for other committees that are responsible to provide us with the guarantees that is it so. Therefore, we view them [generics] with hesitation.' (D4)

even generics are expensive in Greece compared to other European countries.' (D5)

... Also there is the issue with the cost of generics, which should be proportionate to each product's effectiveness ... there has been a negative publicity regarding generics mostly in the electronic media ... but because I believe there is a general lack of trust in the system not just in the National Medicines Agency, from which starts patients' and physicians' distrust towards generics.' (D7)

(B) Safety and effectiveness of generics - Quotes

'Here in Greece we have used generics for many years and we were never made aware that these medicines, generic medicines, are not good ... Because all these products are authorized by the National Medicines Agency, they perform checks ... I haven't seen any difference in effectiveness compared to the originator product. I take generic medicines myself.' (D2)

'I have no complaint from the generic [drug] products that I have used so far, but I have used specific products either Greek ones or imported but all products with a brand-name... I cannot answer on a product that I have not used, I am satisfied with the products I have used ... [regarding effectiveness] I have some reservations for specific products which I have stopped using, I don't remember exactly but there are 2-3 among all generics that are not ... but ok this is understandable there must be 2-3 among all originator products that do not perform as we want them to ...' (D3)

. They are products that undergo checks, have the same active substance as the originator product and of course are equal to the originator medicines and can be prescribed without fear as long as they have undergone all checks that are now obligatory for every generic product ... I believe that generics are effective and as safe as the originator products, always given that the specifications are in place and the necessary checks have been made.' (D6)

'... I cannot imagine why a factory that produces a generic medicine will not use the necessary quantity of active substance, I cannot imagine it, it is above all stupid both commercially and professionally to acquire a bad name ... therefore among generic drug products there are many that are as good as the originator products.' (D9)

'... In this case I would not risk it ... I would not risk prescribing a generic ... because the medicine's therapeutic range is such that it might in the specific case cause problems because it is one thing that is 100\% effective... I don't know what the range in the efficacy of the active substance among generics compared to the originator product is.' (D5)

'I really don't know, I am not convinced as to what takes place in Greece by Greek companies, for example to what degree they are supervised by the National Medicines Agency, if they proceed to the required checks ... to the degree that they are properly regulated and are available in the market for a sufficient time period and are used and as long as they are authorized, I would tend to believe that they are as effective.' (D8)

'There are Greek companies that are established in the field and through the market for cardiovascular medicines and you know this market is somewhat sensitive because you can lose a patient to a wrong medicine, therefore for me this is a guarantee, when the company is already established ...' (D3)

'In Greece we know the companies, who they are, because they all produce generics and they have established themselves all these years. Now, if you come to me with a company of ambiguous origin, what can I tell you? ... No colleague has experience lregarding effectiveness] of imported generics -I mean those from Eastern countries not from European ones- time will tell ...' (D4)

there are big companies that have proven their reliability through their long term presence in the healthcare market, hence this is a guarantee for the physician, because I do not have the mechanisms nor the knowledge to perform checks.' (D5)

‘.. you will have to persuade me that this company is reliable ... when it will have bioequivalence studies from acknowledged centers, for example there are such centers in Canada, Germany etc ...' (D3)

.. I think it has to have a presence in the pharmaceutical market and a validity that a company acquires through its presence in the market, its interactions with physicians and its presence in the bealthcare market in general. After that, let the state establish rules... that give you the impression that a company follows specific rules and is inspected by the state mechanisms ... 


\section{Table 1: Quotes on categories and subcategories from physicians (Continued)}

'Characteristics of a company's reliability are not about luxurious offices and factories....nor about how sufficient its network is and the number of its representatives or about how often they visit you to inform you about their product, nor about the informational material. Of course, in general, the best companies have a better presence regarding all the above and their informational material is simpler, provides answers to critical issues and in a scientific manner on their products' effectiveness ... good generics companies are those that demonstrate good results in certain studies.' (D9)

\section{Category 2: Decisions on prescribing and choice of medication}

(A) Criteria relating to the prescribing decision - Quotes

... depending on the [therapeutic] goals that are set on the basis of international standards ... the medicinal product must be effective, that is it must bring the patient near the desirable goals. This is its effectiveness and in parallel have the least possible side-effects ...' (D3)

$\therefore$ and after so many years ... in any case I have an impression on each product on where it is helpful and where it is not ...'

(B) Criteria they apply when generic versions of the originator drug product are available - Quotes

'The most important product characteristic on which someone should base his decision is whether there are bioequivalence studies available... The fact that the product has the active substance says nothing ... its release time, its absorbability, all these are important for all medicinal products ... whether they have undergone tests and have the same or similar clinical results as the originator.' (D1)

$\therefore$ their excipients, their effectiveness when prescribed to patients, which we see every day and we know each generic medicine '(D6)

'... if we have used this product in the hospital and we were familiar with it ...' (D8)

$\therefore$ the first thing that comes to mind is the brand name of the product [of the originator]... so you think first of the product that is known to you ... therefore I would not say that it is my first choice [the generic one].' (D1)

'... of course a generic [is my first choice], as long as there is one, I will prefer a generic ...' (D2)

'There are bundreds of companies and hundreds of products, I chose some originator products that are established or generics by companies that have been in the Greek market for years ...' (D5)

'Greek companies are based here, we know that there is control. [I havel trust in the Greek companies, we do not know what happens in Africa or Swaziland but here we know, there is the National Medicines Agency and we know those that produce the medicines ...' (D2)

'Any pharmaceutical treatment, any medicinal product that I will prescribe must have a name... I want the $x$ product of the $y$ company' (D3)

'Of course I will prescribe a medicine from a Greek company, which has survived because it is a serious one not opportunistically because there are also these companies...' (D4)

'... we know the companies, which ones operate on a European or international level ...' (D6)

'The criterion of cost to the patient and to social insurance organization ...' (D5)

'... the patient's wishes and in this case I play an advisory role regarding the medicinal products I am familiar with. There are a

lot of patients that ask for a generic drug because of the financial difficulties ...' (D4)

'... if the patient prefers an originator product he pays for it and he can take it ...' (D2)

In many patients we prescribed generics, some patients did not want to change their medicine, it is the box they are familiar with ... they are psychological the reasons they don't want to switch to generics ... this is the behavior in $70-80 \%$ of patients. When they will not have money anymore, only then will they switch. The time is near.' (D3)

\section{Category 3: Attitudes on the measures implemented by the government to promote penetration of generics}

\section{(A) Views on specific measures - Quotes}

'Personally I never follow them [the prescribing protocols] ... I am not even familiar with them. I follow the guidelines developed by scientific associations - the European and American Cardiology Association ... The National Medicines Agency essentially translates these guidelines.' (D1)

'I have no knowledge of them [the prescribing protocols, I want to be bonest, what are they?' (D8)

'They are belpful and have facilitated many physicians on the way to prescribe and the changes to prescribing all these substances that until now were prescribed by brand name.' (D6)

INN prescribing perplexes things somewhat... I do not know whether it will help in the long run ... As long as the pharmacist takes responsibility for the medicinal product be dispenses, I do not have any objections.' (P2)

'I fundamentally disagree with it [INN prescribing] ... because the discussion with the patient regarding the cost and the choice of medicinal product could be done by me as it was done before this measure was introduced ... hence I fundamentally disagree. I am responsible, yes the active substance is the same but I cannot be sure about all available products that they all have bioequivalence studies nor do I consider the State reliable ...' (D3) 


\section{Table 1: Quotes on categories and subcategories from physicians (Continued)}

‘... until now we were used to prescribing using the commercial name, using the INN has its pros and cons ... I believe there could be a combination of both ... I believe that this [generic substitution] should be under the physician's jurisdiction, not the pharmacist's ... because the physician is the one who decides on the therapeutic regiment and should have a say also on the medicinal product.' (D6)

'... regarding INN prescribing I would consider it good in the sense that to a large extent it removes these little games that existed between companies, physicians, pharmacists ... as long as beside economic parameters there are also scientific ones that are taken into account ... that is for example we prescribe by the INN we do not need to take the cheapest product available just because it is the cheapest one, we have to be sure that the patient is given a good medicinal product ... it is very bad lgenerics substitution by the pharmacist ... I do not trust the pharmacists ... and anyway there is the international practice, nowhere in the world do pharmacists choose the medicine, they are only given with a physician's prescription' (D8)

(B) Suggestions towards a successful generics policy - Quotes

'... if we are all convinced that any generic medicine that we may take is as safe and effective, I believe that the cost of pharmaceutical care will fall. If we are not convinced we will always turn to the originator product ... medicines should be prescribed to those who really need them, if this is done and with low cost you will not need to deny anyone access to bis medicines.' (D1) ... there could be an informational campaign that we [the respective agencies] ensure that generics are good medicines and all people can feel free to take whichever product they want ... [this information could be provided] through articles in the press, in medical journals, through medical conferences ... you can organize a campaign not to promote generics but to discuss and create the feeling that their use is not dangerous ... this campaign could be done through TV commercials, presentations in medical conferences, journals, e-mails, anything ...' (D5)

\section{Category 2: Decisions on prescribing and choice of medication}

The most frequent health problems and conditions that physicians prescribe medicines for, in the case of cardiologists, were hypertension, dyslipidemia, type 2 diabetes as well as coronary heart disease, valvulopathy, and other types of heart disease. In the case of general internists the most frequent conditions they prescribed medicines for were hypertension, type 2 diabetes, chronic obstructive pulmonary disease, and also gastrointestinal diseases and acute infections.

\section{2a. Criteria relating to the prescribing decision}

When asked about the factors that they take into consideration when deciding on which medicine to prescribe to a patient, participants made reference to a multiplicity of factors. The major factors were disease characteristics (8/9), patient characteristics (9/9) and medicinal product characteristics (6/9). Disease characteristics included the need to prescribe a medicine for the specific indication, the acuteness of the specific episode, whether the disease is chronic, the disease duration (time from onset) and the therapeutic goals the physician sets. Patient characteristics referred to their age, sex, weight, coexisting health conditions and comorbidities, laboratory results, family as well as personal health history, allergies, but also to one's emotional state, expected compliance with the prescribed pharmacotherapy, income and lifestyle. One participant made the distinction that if the patient was regularly followed by another physician, he/she would not consider changing the patient's medicine.

Finally, when deciding on the medicinal product of choice, physicians claimed that they consider primarily its indications (4/9), effectiveness (4/9) and side effect profile (3/9). Their personal experience with prescribing a medicinal product to patients was mentioned by some participants as an input on the product's effectiveness.

\section{2b. Criteria they apply when generic versions of the originator drug product are available}

In the specific case when both the originator drug product as well as its generic versions are available in the market, physicians also apply the aforementioned criteria of effectiveness and safety. These are the most important ones, but they also consider additional factors. Effectiveness is evaluated on the basis of the product's bioequivalence studies (4/9) and also on the basis of previous experience (2/9) with specific products either in his/her private practice or in other settings the physician has worked in. Also, physicians state that over time they have established their preferences regarding the type (originator/generic) and number of products that they prefer to prescribe (3/9).

The marketing authorization holder is considered an important parameter in product choice, as it is considered a proxy of the product's reliability (8/9). Greek companies that have been present for a long time in the market were used by many participants as examples (5/9), although some physicians also distinguished among them (2/9). Doubts were expressed mostly on generics that are imported from other countries, i.e. products for which physicians had no knowledge or experience with (4/9). Preference towards locally produced generics was also seen as a means to support the country's economy (4/9). Other criteria for selecting among available products with the same active substance are their price (and consequently the cost to the patient) (4/9) and patient's preferences (5/9).

The choice between originator and generic medicine was seen by some physicians (3/9) as a factor of their image, i.e. their 'status' as a doctor. This was because of the negative image that was created during the past years regarding the relations between companies and physicians, and the view that the choice of type of drug is an indicator of the quality of the services that a physician provides. However, opposing views were also expressed (2/9), with participants arguing that a physician's reputation and professional experience are more important evaluation criteria for patients than the choice of drug. 
Category 3: Attitudes on the measures implemented by the government to promote penetration of generics

The measures introduced with the aim of promoting generics' consumption were in general acceptable by the majority of the participating physicians (6/9). They saw them as means to decrease public pharmaceutical expenditure and prices of pharmaceuticals. However, they expressed criticism on the actual way that these measures were implemented (3/9) which, according to their opinion, created a negative impression among the public and suggested that the effort towards rationalizing expenditure should not be based on imposed decisions through the MoU. Two participants expressed very negative opinions on the respective measures. They were seen as part of a series of measures that constituted a change in health policy in a wrong direction, especially regarding the impact on the Greek industry and subsequently, economy.

\section{3a-3d. Views on specific measures}

Electronic prescribing was positively evaluated and was thought to facilitate promotion of generics (6/9). The occasional technical problems of the system were considered as its only drawback. Participants' opinions regarding the prescribing protocols that were developed by the National Medicines Agency varied. Some physicians were not aware of their existence (4/9) and, among those that were aware, some believed that they were helpful (3/9) whereas others reported that they never used them as they made decisions based on international scientific guidelines or on their experience (2/9).

Participants expressed opposing views on INN prescribing. This measure was seen as a way to cope with financial ties between physicians and pharmaceutical companies (2/9), but there were reservations regarding its purposefulness (3/9). Specifically, participants expressed criticism to the fact that the prescribing physician could not choose the prescribed medicine and suggested that there were alternative means, such as a combination of INN and brand-name prescribing or discussing with a patient about prescribing a generic medicine (3/9). The majority of physicians were negative on generics substitution by pharmacists during dispensing (7/9). They believed that it deprived the physician of control over the dispensed medicinal product, since the physician cannot be familiar with all the available generic drug products, and that it could also lead to frequent changes between generic drug products. An issue that was raised by many participants was the impact of generics substitution on physician and pharmacist roles and the need to clarify which health professional would be held responsible (5/9).

Additional measures that are foreseen in the MoU and are to be implemented in case the pharmaceutical expenditure targets are not met (i.e. the cost/patient plafond - an average 'target' for pharmaceutical spending for each patient that the physician monitors and prescribes medication for depending on physician specialty and diagnosis, and the maximum prescribing targets/ physician) were rejected by all participants, as they were characterized as horizontal, unjust to the patients and offensive to the physicians. They also considered that they were difficult to implement from a technical point of view.

\section{3e. Suggestions towards a successful generics policy}

Physicians again stressed the need for competing organizations to ensure that the products that are available in the market will be effective and reliable. As long as this prerequisite was met, further measures to promote generics consumption could include the promotion of rational prescribing among physicians, reductions in prices of generics through either free pricing or discount agreements with the local industry, and informational campaigns by the National Medicines Agency targeting both physicians and patients.

\section{B. Patients \\ Patients' quotes are presented in Table 2.}

\section{Category 1: Knowledge and sources of information on pharmaceuticals for their chronic disease}

All patients could name the medicinal products they were taking for their chronic health problems. All but one also knew whether these were the originator products or generics and in most cases (8/9) patients stated that their medicines were originator products.

Interviewed patients had different behaviours regarding information seeking on the medicines they take: patients who were not actively seeking such information (3/9) claimed that they do not take many medicines, that they follow their physician's orders and that they are satisfied with the medicinal products they have been using for years. Among those that were interested in obtaining information on their medicines (6/9), their main source of information was their physician (6/9), whom they saw as the most reliable source. The pharmacist was also an important source (4/9), provided that patients felt they had a trusting relationship similar to the one with their physician. Complementary sources of information were the product's package insert with information for the user, the Internet and - for some patients their social environment. The type of information that is the most important to them is possible side effects (5/9), effectiveness $(5 / 9)$ and interactions with other medicines (2/9). Some patients also mentioned the product's dosage and composition (3/9).

\section{Category 2: Factors regarding the choice of their medications 2a. Choice of medication}

For almost all participants (8/9), the choice of prescribed medication was made by the physician. For some patients (2/9) the physician had informed them of available therapies and the rationale for choosing the specific medicine, whereas for other patients there was no discussion with the physician. Only one patient claimed that because he/she could not afford the cost of a visit to the physician, the pharmacist was the one that gave him/her a medicinal product similar to the one he/she was taking and was not available in the market anymore.

\section{2b. Factors that they consider regarding the choice of medication}

Patients claimed that cost (in terms of the patient's copayment) was not a decisive factor in their choice of medicinal product (7/9). Although the majority of participants was subject to copayment (8/9), some stated that they would not consider cost at all if it was necessary to take a more expensive medicine that was suitable for them (4/9). For other patients cost would be a consideration but not the most important one; effectiveness and side effects would be the main criteria of choice (3/9). Patients with chronic conditions who were subject to a lower (10\% instead of $25 \%$ ) co-insurance rate said they were more 


\section{Table 2: Quotes on categories and subcategories from patients}

Category 1: Knowledge and sources of information on pharmaceuticals for their chronic disease

1a. Knowledge on their medicine

1b. Information sources and evaluation of their quality

1c. Preferences and suggestions

'I have not looked for information, except for that given by the physician. I haven't searched the Internet ... I take [this medicine] for years and I do not look for information [on the medicines] ...' (Patient 1)

'In general, I trust my physician and I am not concerned with looking for more information, I have trust in the medicine my physicians prescribes for me... (Patient 2)

'I get] information on medicines mostly from the pharmacist, I ask her when the physician prescribes something ... I have known ber for years, the pharmacy is just opposite my house, I trust her a lot.' (Patient 4)

'I use many sources: from friends, physicians, perhaps the Internet, but mostly by talking to friends that have the same health problem.' (Patient 6)

\section{Category 2: Factors regarding the choice of their medications}

2b. Factors that they consider regarding choice of medication

'No, to me not [the copayment amount is not a criterion of choice] ... no matter bow difficult your financial situation is if you have to take an expensive medicine, as long as you can bear the cost at least you will take it.' (Patient 2)

'Yes of course [the copayment amount is not a criterion of choicel because at the moment it is high ...' (Patient 6)

'If I did not have zero co-payment because of another disease, cost would be a criterion... No [cost] would not be the primary criterion, the primary criteria would be its effectiveness and side effects ...' (Patient 8)

'Yes [I would be willing to switch to a generic drug] as long as the physician assured me that it is equivalent ... if the physician considered that the effect on my blood pressure would be the same I would take it yes ...' (Patient 2)

'Now with the new way of prescribing the physicians prescribes the active substance and I ask the pharmacist for the specific product, the one I take ... but last time I asked at the pharmacy if we could switch to a generic drug the difference in cost was so small I did not change my medicine.' (Patient 6)

'No [I would not be willing to switch to a generic drug] if I weren't sure that it is the same as the originator, I can't be sure of it so I don't take generics. Because there is nothing that would make me certain, I choose the originator products.' (Patient 9)

'My opinion at the moment, I can't say ... I have the impression that the originator, because we have tried it in my family, is much better... I don't trust them [generics] because they are new in the market and I don't trust them, I don't know where they will come from. From which country they will come from ...' (Patient 1)

'I haven't looked into it, I am very little informed. I don't know' (Patient 2)

'My opinion on generics is positive, there are good and bad generics as there are good and bad originator products.' (Patient 6)

3c. Views on the measures implemented by the government to promote consumption of generics

'No I have no confidence [in generics substitution] because I cannot decide and I don't have the knowledge and the information . No I don't believe that the pharmacist will dispense the cheapest generic drug. If the patient does not know which medicine to take ... this is what I think that he will promote the generic drug product that is more profitable, this is my impression.' (Patient 1) 'I see it [INN prescribing] as a good thing because I believe that medicines are cheaper and the consumer pays less ...' (Patient 4) 'I don't think it is right, I think the physician should choose the medicine and not the pharmacist... he is more competent to decide, no matter how similar to the originator it is there may be certain differences in side effects for instance.' (Patient 9)

likely to consider cost had their co-insurance been higher. Cost was an important parameter of choice for one participant, who reported having a high copayment.

On the matter of switching to a generic medicine, the majority of patients expressed willingness to try switching to a generic drug product (7/9), however, only if their physician or, in some cases, a pharmacist they trusted, suggested a switch to a specific product and they felt that it had the same effectiveness and side effect profile as the originator product. Few participants reported that they had discussed with pharmacists on the available alternatives but the difference in cost was not considerable so as to choose a generic drug (2/9). In one case, the patient precluded switching to generics because he/she considered that there was no way to ensure that generics were the same as the originator product.

\section{Category 3: Generic medicines}

\section{3a. Attitudes on generics}

Participants' views on generics varied. The majority was reluctant to express a definitive opinion as they felt they were not adequately informed (4/9) whereas, others expressed both negative (2/9) and positive views (2/9). Among those that were hesitant towards generics, there was a concern regarding the regulatory mechanisms in place to check their safety and regarding the country of origin. The impression that the main purpose for promoting generics consumption was to cut public pharmaceutical expenditure also had casted doubts on their quality.

\section{3b. Sources of information and information needs}

All patients replied that they have heard 'something' on generics through various sources, such as the mass media (newspapers, 
$\mathrm{TV}$, radio, the Internet), friends, the pharmacist, companies' promotional leaflets and medical conferences. Most patients had not been informed or had not initiated a discussion with their physician on generics (6/9). Participants felt that the mass media were a source of more general information on generics and that someone that wanted to inquire about his/her specific treatment would ask their physician, whom they considered the most reliable source of information, followed by the pharmacist. The type of information they would want to be available includes what generics are, why they exist, their country of origin and quality control mechanisms in place by the local authorities, their effectiveness and safety in relation to the originator products and their cost. Patients preferred to be informed by their physician on generic medicines for their health problems; however, they thought that physicians do not have the time or intention to provide such information. Pharmacists, the National Medicines Agency and the Ministry of Health or other independent organizations and leaflets were suggested as complementary sources of information.

\section{3c. Views on the measures implemented by the government to promote consumption of generics}

Patients expressed conflicting views on INN prescribing and generics substitution. Those that held a positive view (5/9) argued that the measures ensure access to a safe and effective medicine without preventing the patient to choose a different product, that they contribute to the financial sustainability of social insurance and that they also provide low cost alternatives to patients. On the other hand, arguments against the measures were related to the patients' lack of knowledge so as to decide over a generic product, the financial motives that might affect the pharmacists' behaviour and also to the view that the physician should be the only person responsible for choosing a specific medicinal product for the patient.

\section{Discussion}

Physicians in our study expressed varying views on generic medicines. Those that had a positive attitude towards generics expressed a preference towards locally produced products with which they were familiar and they felt confident to prescribe. Physicians claimed that the generics company was important in their choice of generic product. Ensuring that available products in the market are safe and effective and meet the foreseen standards was a precondition for their use that was raised as an issue by both physicians and patients.

Quantitative research efforts on generics prescribing and Greek physicians' attitudes that were conducted before the economic crisis had shown that although physicians in general had a positive attitude towards generics, they chose to prescribe originator medicines [17]. This behavioural inconsistency in Greek physicians was attributed to inadequate provision of information on generics at the university level, lack of trust in the procedures for marketing authorization of generic drug products, and the absence of financial incentives (the very small price differentials between originator and generic drugs) [17, 26]. Another study conducted in Greece showed mixed opinions among general practioners (GPs) regarding the effectiveness of generics and highlighted the bad reputation of generics in Greece as one of the main factors for their low market share [27].
Patients in this study also appeared hesitant towards the use of generics, whereas, they considered that more information on those products was necessary. This is in line with findings of quantitative studies that were conducted after the first EAPrelated policy measures were adopted $[28,29]$ as well as more recent ones $[30,31]$.

According to our findings, prescribing is a multi-criteria decision based on the characteristics of the disease, the patient and the medicinal product. This finding is confirmed by a number of studies in the literature that suggest that the prescribing decision is a balance between effectiveness, safety, cost and patient preferences [32]. Other factors such as colleagues, patients, pharmaceutical sales representatives may affect prescribing decisions in general [33] as well as for generics in specific [27]. Pharmaceutical sales representatives had been acknowledged as the main information resource of physicians in other studies as well [17, 26]; according to our findings this source of information remains active, despite the implementation of INN prescribing. This may be explained by the fact that at the early steps of INN prescribing implementation in Greece, physicians had the option to (partially) prescribe by brand name - and thus, established generics companies tried to secure their market share.

On the other hand, for the patients, their physician's opinion was the most important factor for switching to a generic drug product. Cost was a consideration for some patients, however, but not the primary one and also, at the time of study, cost differentials between generics and originators were not strong enough. This is confirmed by a quantitative cross-sectional study conducted in Greece which investigated the response of patients with chronic conditions to the measure of INN prescribing and found that the majority of the participants (82\%) were not willing to change their usual drug and switch to a generic drug despite the extra cost they had to bear [34]. In the study of Skaltsas and Vasileiou (2015) patients acknowledge the lower cost of generics as their main advantage - however their physician or pharmacist plays the most influential role in their choice [31].

Finally, physicians in general seem to accept most of the policy measures implemented towards generics' prescribing and consumption, however they believe that more actions are necessary, such as more competitive prices for generics and informational campaigns for physicians, patients as well as pharmacists. Similar views were expressed by key stakeholders of the Greek pharmaceutical market regarding the generics policy measures [35]. However, INN prescribing and generics substitution were met with skepticism by participating physicians.

Our findings are in line with those of similar studies in the international literature. Physicians' beliefs regarding the quality and effectiveness of generic medicines and level of trust in their marketing authorization procedures significantly affect their decision to prescribe generic medications [36-39]. Furthermore, patients' consumption of generics is also associated with their perceived quality, although additional factors such as patient's characteristics, health literacy, sources of information on generics and cost considerations have a significant impact as well [38, 40-42]. 


\section{Strengths and limitations}

Qualitative studies present significant advantages but also suffer from some limitations mainly due to their small sample size and the ability to generalize their findings. In order to address these issues, adherence to international guidelines for qualitative research is essential. In the case of the present study, the methodology was based on the COREQ checklist [43], a widely acknowledged set of guidelines. In this study, our findings come from rather homogeneous and small samples and may not be generalizable to the medical community or patients with all types of chronic disease. However, in the present study sampling continued until data saturation was achieved, meaning that no new additional thematic categories and data emerged. Also, although the recruitment was based on convenience and snowballing techniques, specific criteria were applied (as stated in the methods section) and the study focused on specialties and patients that are most likely to prescribe or consume generics, resulting to the fact that participants were more familiar with the research question. Another controversial issue in the qualitative studies is whether to use numbers to present the results [44]. Several arguments have been presented favouring the one or another view, but the most common approach is to semi-quantify the results when possible, using illustrative quotes to support the results [45]. Finally, the study was conducted in a rapidly changing environment. Further reductions of generics prices were adopted shortly after the completion of our study, which may have an effect on participants' perceptions of generics prices levels. However, in our study, cost was not the most important factor to patients for switching to a generic medicine and, price reductions have not yet led to an increase in generics market share. A study conducted at a national level in 2014 shows that there is still poor acceptance of the introduced measures regarding generics among physicians [46]. Therefore in our opinion, the fact that our results are in line with other published studies proves that the major issues that emerged in our study remain valid. Finally, our study is to our knowledge the only published qualitative study that explores physicians and patients views on generics and INN prescribing giving answers to the rationale behind these views.

\section{Potential policy implications and future research}

Greece has significantly reduced public pharmaceutical expenditure in a short time frame; still, the market share for generics is below the target set in the EAP [19]. The results of our study suggest that physicians and patients have established behaviours and attitudes towards generics, which have not significantly changed despite the policy measures to promote generics consumption. Furthermore, their main concerns remain unaddressed. Addressing physicians' and patients' concerns and aligning the incentives in place for all actors in the pharmaceutical market have been acknowledged as core enabling factors for the successful implementation of a generics policy [47]. Specifically, the fact that the policies regarding generics were implemented during the financial crisis in order to contain pharmaceutical expenditure, created doubts on their quality. Therefore, official regulatory bodies should perform additional quality assurance in order to tackle safety and quality concerns. Also, there is a need for reliable information from regulatory and other bodies to dispel the myths regarding generics and convince patients (through their physicians) that generics are not only cheap but effective and safe as well. Finally, the results of our study can be used in future research in order to develop more targeted quantitative research questionnaires and to form specific research questions.

\section{Conclusion}

The present study, due to its qualitative methodology elicited the major concerns regarding generics among prescribing physicians as well as among patients and, also, identified their main sources of information and information needs. The information available in studies such as the present one, can aid decision-makers towards the design and implementation of viable policies in the sensitive field of generics uptake.

Acknowledgements: The authors would like to thank all interviewed physicians and patients for their participation.

Disclosure of financial and competing interest: No funding was obtained for this study. The authors declare no conflict of interest.

Provenance and peer review: Not commissioned; externally peer reviewed.

\section{Contributing authors}

Eleftheria Karampli, Vasiliki Tsiantou, Kostas Athanasakis and John Kyriopoulos were involved in study design. Efstathia Triga interviewed participants, transcribed interviews, conducted content analysis and interpreted the results. Eleftheria Karampli analysed interview transcripts, interpreted the results and drafted the manuscript. Vasiliki Tsiantou assisted in data analyses and drafted the manuscript. Kostas Athanasakis assisted in data analyses and critically revised the manuscript. JK provided scientific guidance, supervised the study design and revised the manuscript for critically important intellectual content.

\section{Authors \\ Eleftheria Karampli, MSc \\ Efstathia Triga, MSc \\ Vasiliki Tsiantou, MSc \\ Kostas Athanasakis, PhD \\ John Kyriopoulos, PhD}

Department of Health Economics, National School of Public Health, 196 Alexandras Avenue, GR-11521, Athens, Greece

\section{References}

1. OECD. Pharmaceutical Pricing Policies in a Global Market. OECD Health Policy Studies. Paris: OECD Publishing; 2008.

2. Sorenson C, Drummond M, Kanavos P. Ensuring value for money in health care. The role of health technology assessment in the European Union. Copenhagen: European Observatory on Health Systems and Policies; 2008.

3. Barros PP. Pharmaceutical policies in European countries. Ad Health Econ Health Serv Res. 2010;22:3-27.

4. Kanavos P. Measuring performance in off-patent drug markets: a methodological framework and empirical evidence from twelve EU Member States. Health Policy. 2014;118(2):229-41

5. Mladovsky P, Srivastava D, Cylus J, et al. Health policy responses to the financial crisis in Europe. Copenhagen: WHO Regional Office for Europe; 2012. 
6. Vogler S, Zimmermann N, Leopold C, et al. Pharmaceutical policies in European countries in response to the global financial crisis. South Med Rev. 2011;4(2): 22-32.

7. Leopold C, Mantel-Teeuwisse AK, Vogler S, et al. Effect of the economic recession on pharmaceutical policy and medicine sales in eight European countries. Bull World Health Organ. 2014;92(9):630-40D.

8. European Commission Directorate-General for Economic and Financial Affairs. The Economic Adjustment Programme for Greece: Fourth Review Spring 2011. Brussels: European Commission, Directorate-General for Economic and Financial Affairs; 2011.

9. Godman B, Shrank W, Wettermark B, et al. Use of generics-a critical cost containment measure for all healthcare professionals in Europe? Pharmaceuticals. 2010;3(8):2470-94.

10. Vogler S. The impact of pharmaceutical pricing and reimbursement policies on generics uptake: implementation of policy options on generics in 29 European countries-an overview. Generics and Biosimilars Initiative Journal (GaBI Journal). 2012;1(2):93-100. doi:10.5639/gabij.2012.0102.020

11. Godman B, Bishop I, Finalayson AE, Campbell S, Kwon HY, Bennie M. Reforms and initiatives in Scotland in recent years to encourage the prescribing of generic drugs, their influence and implications for other countries. Expert Rev Pharmacoecon Outcomes Res. 2013;13(4):469-82.

12. Kesselheim AS, Misono AS, Lee JL, Stedman MR, Brookhart MA, Choudhry NK, Shrank WH. Clinical equivalence of generic and brand-name drugs used in cardiovascular disease: a systematic review and meta-analysis. JAMA. 2008;300(21):2514-26

13. Garuoliene K, Godman B, Gulbinovič J, Wettermark B, Haycox A. European countries with small populations can obtain low prices for drugs: Lithuania as a case history. Expert Rev Pharmacoecon Outcomes Res. 2011;11(3):343-9.

14. European Commission Directorate-General for Economic and Financial Affairs, The Second Economic Adjustment Programme for Greece - Fourth Review April 2014. Brussels: European Commission Directorate-General for Economic and Financial Affairs; 2014.

15. Greece's health minister sets ambitious new targets for generics prescribing, penalties for violations. IHS. 2015 Feb 11.

16. European Commission. Memorandum of Understanding between the European Commission acting on behalf of the European Stability Mechanism and the Hellenic Republic and the Bank of Greece. 19 August 2015 [homepage on the Internet]. [cited 2016 Apr 8]. Available from: http://ec.europa.eu/economy_finance/ assistance_eu_ms/greek_loan_facility/pdf/01_mou_20150811_en.pdf

17. Tsiantou V, Zavras D, Kousoulakou H, et al. Generic medicines: Greek physicians' perceptions and prescribing practices. J Clin Pharm Ther. 2009;34(5): 547-54.

18. Vandoros S, Stargardt T. Reforms in the Greek pharmaceutical market during the financial crisis. Health Policy. 2013;109(1):1-6.

19. Mylona K, Karampli E, Boubouchairopoulou N, et al. [Pharmaceutical technology management and evaluation in Greece: a political economy of health perspective]. Greek. Athens: Kastaniotis. 2015:83.

20. Abusabha R, Woelfel ML. Qualitative vs quantitative methods: two opposites that make a perfect match. J Am Diet Assoc. 2003;103(5):566-9.

21. Byman A. Social Research Methods. 4th ed. New York: Oxford University Press. 2012.

22. National School of Public Health. Healthcare services evaluation survey - Part 2: healthcare services utilisation. Athens: National School of Public Health/ Special Research Account; 2011 [homepage on the Internet]. [cited 2016 Apr 8]. Available from: http://www.esdy.edu.gr/default.aspx?page=toy_ereynes_toy

23. Hardon A, Hodgkin C, Fresle D. How to investigate the use of medicines by consumers. World Health Organization and University of Amsterdam; 2004.

24. Hsieh HF, Shannon SE. Three approaches to qualitative content analysis. Qual Health Res. 2005;15(9):1277-88.

25. Guest G, Bunce A, Johnson L. How many interviews are enough? An experiment with data saturation and variability. Field Methods. 2006;18(1):59-82.
26. Theodorou M, Tsiantou V, Pavlakis A, et al. Factors influencing prescribing behaviour of physicians in Greece and Cyprus: results from a questionnaire based survey. BMC Health Serv Res. 2009;9:150.

27. Tsiantou V, Shea S, Martinez L, et al. Eliciting general practitioners' salient beliefs towards prescribing: A qualitative study based on the Theory of Planned Behaviour in Greece. J Clin Pharm Ther. 2013;38(2):109-14.

28. Slideshare. Generics in Greece, research by TNS Icap and Baas [homepage on the Internet]. Greek. [cited 2016 Apr 8]. Available from: http://www. slideshare.net/panayiok/generics-in-greece-research-by-tns-icap-and-baas

29. Hellenic Pharmaceutical Industry Association. [Confidence in branded generics of Greek origin]. 20 September 2012. Greek.

30. Mylona K, Skroumpelos A, Zavras D, et al. Chronic patients' perceptions about generic medicines in Greece: findings from a cross sectional survey. Value in Health. 2013;16(7):A469.

31. Skaltsas LN, Vasileiou KZ. Patients' perceptions of generic drugs in Greece. Health Policy. 2015;119(11):1406-14.

32. Barber N. What constitutes good prescribing? BMJ. 1995;310(6984):923-25.

33. Tsiantou V, Moschandreas J, Bertsias A, et al. General Practitioners' intention to prescribe and prescribing patterns in selected European settings: the OTCSOCIOMED project. Health Policy. 2015;119(9):1265-74.

34. Mylona K, Skroumpelos A, Zavras D, et al. Chronic patients response to the implementation of International Non-Proprietary Name (INN) prescribing in Greece. Value in Health. 2013;16(7):A470.

35. Karampli E, Tsiantou V, Mylona K, et al. Stakeholders's views on recently introduced measures to promote generics consumption in Greece. Value in Health. 2012;15(7):A305.

36. Fabiano V, Mameli C, Cattaneo D, et al. Perceptions and patterns of use of generic drugs among Italian family pediatricians: first round results of a web survey. Health Policy. 2012;104(3):247-52.

37. Shrank WH, Liberman JN, Fischer MA, et al. Physician perceptions about generic drugs. Ann Pharmacother. 2011;45(1):31-8.

38. Kersnik J, Peklar J. Attitudes of Slovene general practitioners towards generic drug prescribing and comparison with international studies. J Clin Pharm Ther. 2006;31(6):57-83.

39. Kumar R, Hassali MAA, Kaur N, et al. Perceptions of physicians from private medical centres in Malaysia about generic medicine usage: a qualitative study. Generics and Biosimilars Initiative Journal (GaBI Journal). 2014;3(2):63-70. doi:10.5639/gabij.2014.0302.019

40. Iosifescu A, Halm EA, McGinn T, et al. Beliefs about generic drugs among elderly adults in hospital-based primary care practices. Patient Educ Couns. 2008;73(2):377-83.

41. Babar ZU, Stewart J, Reddy S, et al. An evaluation of consumers' knowledge, perceptions and attitudes regarding generic medicines in Auckland. Pharm World Sci. 2010;32(4):440-8.

42. Heikkilä R, Mäntyselkä $P$, Ahonen R. Do people regard cheaper medicines effective? Population survey on public opinion of generic substitution in Finland. Pharmacoepidemiol Drug Saf. 2011;20(2):185-91.

43. Tong A, Sainsbury P, Craig J. Consolidated criteria for reporting qualitative research (COREQ): a 32-item checklist for interviews and focus groups. Int J Qual Health Care. 2007;19(6):349-57.

44. Maxwell J. Using numbers in qualitative research. Qualitative Inquiry. 2010; 16(6): $475-82$.

45. Anderson C. Presenting and evaluating qualitative research. Am J Pharm Educ. 2010;74(8):141.

46. Labiris G, Fanariotis M, Kastanioti C, et al. Greek physicians' perceptions on generic drugs in the era of austerity. Scientifica (Cairo). 2015:2015:251792.

47. Kaplan WA, Ritz LS, Vitello M, Wirtz VJ, et al. Policies to promote use of generic medicines in low and middle income countries: a review of published literature, 2000-2010. Health Policy. 2012;106(3):211-24.

DOI: 10.5639/gabij.2016.0501.005

Copyright @ 2016 Pro Pharma Communications International 
Supplementary materials

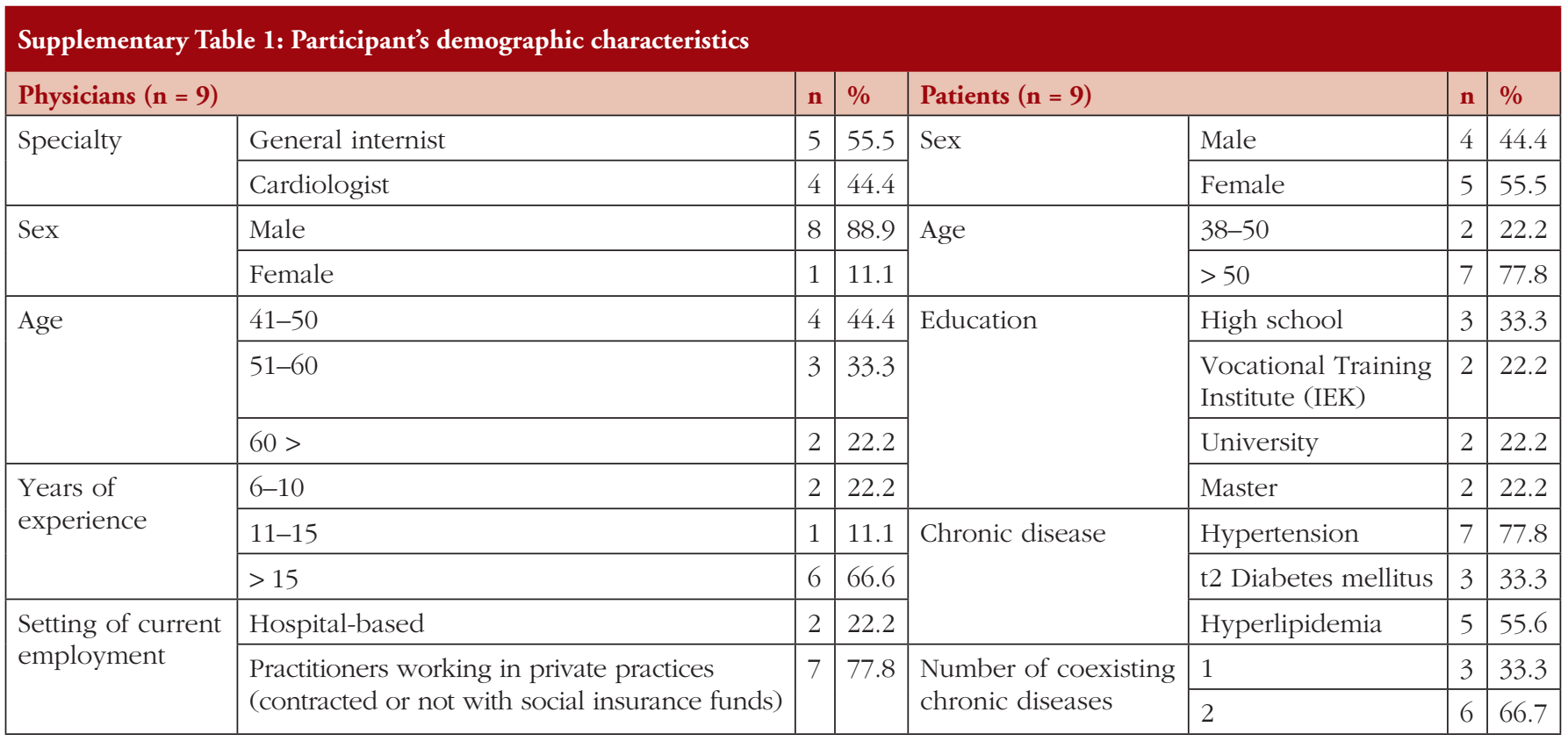

\section{Supplementary Table 2: Main categories and subcategories regarding generics}

\begin{tabular}{|l|l}
\hline Physicians & Patients \\
\hline
\end{tabular}

Category 1: Perceptions about generics and the need to strengthen quality assurance mechanisms in the Greek market

1a. Views on the current situation

1b. Safety and effectiveness of generics

1c. Sources of information on generics

Category 1: Knowledge and sources of information on pharmaceuticals for their chronic disease

1a. Knowledge on their medicine

1b. Information sources and evaluation of their quality

1c. Preferences and suggestions

Category 2: Decisions on prescribing and choice of medication

$2 a$. Criteria relating to the prescribing decision

2b. Criteria they apply when generic versions of the originator drug product are available

Category 3: Attitudes on the measures implemented by the government to promote penetration of generics

3a. Electronic prescribing

3b. Prescription protocols

3c. INN prescribing and generics substitution

3d. Additional foreseen measures

3e. Suggestions towards a successful generics' policy

INN: International Nonproprietary Name.
Category 2: Factors regarding the choice of their medications

2a. Choice of medication

$2 b$. Factors that they consider regarding choice of medication

\section{Category 3: Generic medicines}

3a. Attitudes on generics

3b. Sources of information and information needs

$3 c$. Views on the measures implemented by the government to promote consumption of generics 